\title{
First record of the sea anemone Anthopleura nigrescens (Cnidaria: Actiniaria: Actiniidae) on the Pacific coast of Central America
}

\author{
F.H. ACUÑA ${ }^{1}$, J. ALVARADO ${ }^{2}$, A. GARESE ${ }^{1}$ AND J. CORTÉs $S^{3,4}$ \\ ${ }^{1}$ Instituto de Investigaciones Marinas y Costeras, CONICET, Facultad de Ciencias Exactas y Naturales, Universidad Nacional de Mar \\ del Plata, Funes 3250, 7600 Mar del Plata, Argentina, ${ }^{2}$ Escuela de Ciencias Biológicas, Universidad Nacional, Heredia, Costa Rica, \\ ${ }^{3}$ Centro de Investigación en Ciencias del Mar y Limnología (CIMAR), Ciudad de la Investigación, Universidad de Costa Rica, San \\ Pedro, 11501-2060 San José, Costa Rica, ${ }^{4}$ Escuela de Biología, Universidad de Costa Rica, San Pedro, 11501-2060 San José, Costa \\ Rica
}

\begin{abstract}
We report the first record of the sea anemone Anthopleura nigrescens on the Pacific coast of Central America. Five specimens from Mata Limón (Costa Rica) were collected from rocks of a man-made breakwater at sub-tidal level. Images of live specimens are presented. A map with its worldwide distribution is included and we concluded that this actiniarian can be considered widely distributed in the Indo-Pacific.
\end{abstract}

Keywords: sea anemone, Anthopleura nigrescens, Pacific coast, Costa Rica, Central America

Submitted 10 February 2012; accepted 13 February 2012

\section{INTRロDUCTIDN}

Anthopleura is a common sea anemone genus with 46 widely distributed valid species (Fautin, 2011). Some species are common in the Pacific Ocean, for example A. artemisia (Pickering in Dana, 1846), A. dowi Verrill, 1869, A. elegantissima (Brandt, 1835), A. kurogane Uchida and Muramatsu, 1958, A. mariscali Daly and Fautin, 2004, A. sola Pearse and Francis, 2000, A. xanthogrammica (Brandt, 1835) and A. nigrescens (Verrill, 1928). This last species was described as Teliaopsis nigrescens by Verrill (1928), and then mentioned as Bunodactis nigrescens by Carlgren, 1949 and A. nigrescens by Mathew (1967) and England (1969). Subsequently, Dunn (1974) redescribed this sea anemone in detail, using specimens from Hawaii. The distribution of $A$. nigrescens was extended to the Galápagos Islands and to Singapore by Fautin et al. $(2007,2009)$. In this paper we report the presence of $A$. nigrescens in Mata Limón (Costa Rica), extending its distribution to the Pacific coast of Central America.

\section{MATERIALS AND METHDDS}

Five specimens of Anthopleura nigrescens were collected during a low tide at $0.2 \mathrm{~m}$ depth by one of us (J.A.) from Mata Limón $\left(9^{\circ} 55^{\prime} 01.99^{\prime \prime} \mathrm{N}-84^{\circ} 42^{\prime} 49.50^{\prime \prime} \mathrm{W}\right)$ (Costa Rica) on 8 February 2011. There were more individuals in the field but five specimens were enough to identify the species. All were settled on rocks of a man-made breakwater at a sub-tidal level. The material was fixed in $5 \%$ seawater formalin and preserved in

Corresponding author:

F.H. Acuña

Email: facuna@mdp.edu.ar
70\% ethanol; before preservation some photographs were taken. The five specimens are deposited at the Actiniarian Collection of the Departamento de Ciencias Marinas (Facultad de Ciencias Exactas y Naturales, Universidad Nacional de Mar del Plata) with reference C.A. 28. The general morphology, anatomy and other observations related to the taxonomy of the sea anemones were studied at the Instituto de Investigaciones Marinas y Costeras (IIMyC) (CONICET-UNMdP, Mar del Plata, Argentina) by means of a stereo dissecting microscope. Cnidae were analysed from two individuals using a Zeiss Axiolab microscope with a micrometric eyepiece at a magnification of $1000 \times$ (oil immersion). Cnidae nomenclature follows England (1991).

\section{RESULTS}

SYSTEMATICS

Order ACTINIARIA Hertwig, 1882

Suborder NYNANTHEAE Carlgren, 1899

Infraorder THENARIA Carlgren, 1899

No rank ENDOMYARIA Stephenson, 1921

Family ACTINIIDAE Rafinesque, 1815

Genus Anthopleura Duchassaing de Fombressin and Michelotti, 1860

Anthopleura nigrescens (Verrill, 1928)

(Figure 1)

\section{DESCRIPTION}

Oral disc diameter in the studied individuals is $12-21 \mathrm{~mm}$, approximately equal to that of the basal disc. Height is 9$20 \mathrm{~mm}$. Cylindrical column dark. Variable number of rows of adhesive verrucae. Verrucae are about the same size. Attached gravel covering entirely or partly the column. 

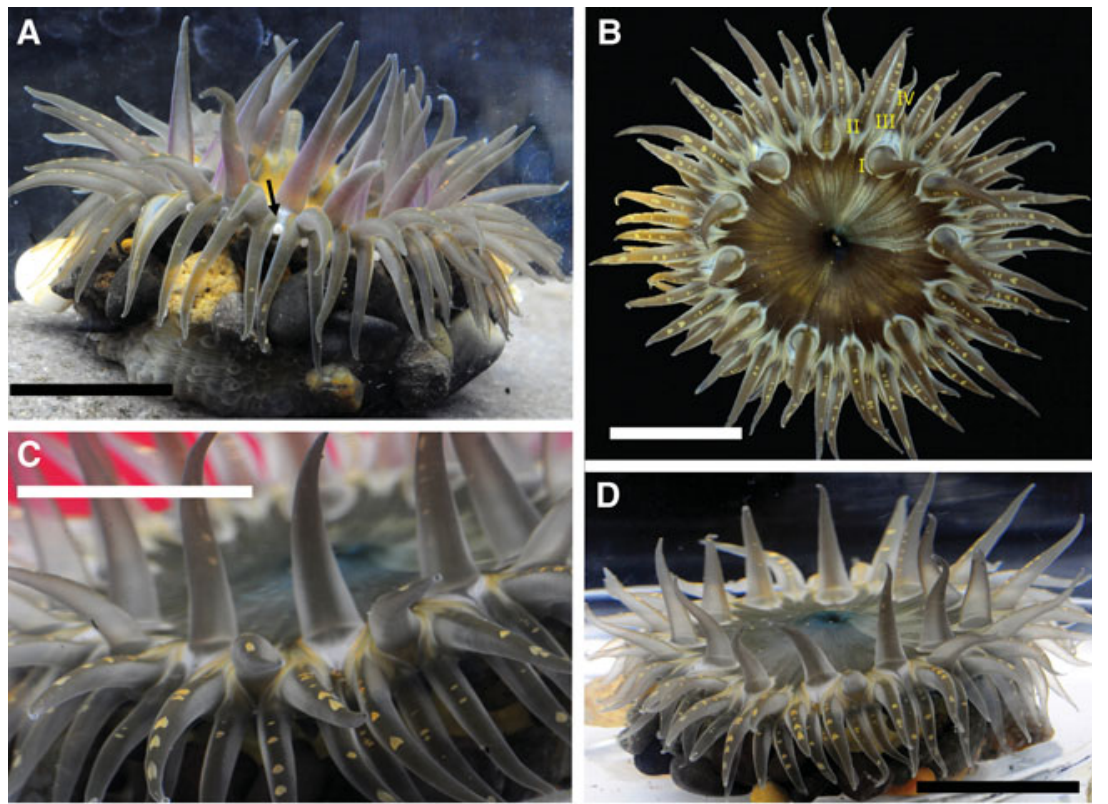

Fig. 1. Anthopleura nigrescens (Verrill, 1928): (A) live appearance showing the attached gravel to the column, verrucae and white acrorhagi (arrow); (B) oral disc with the four (I-IV) cycles of tentacles; (C) tentacles with white-yellow spots on their oral face; (D) specimen extending its oral area into a cone. Scale bar: $1 \mathrm{~cm}$.

Animals in aquarium retain the gravel grains on their verrucae (Figure 1A). 32-80 tentacles arranged in four cycles (Figure $1 \mathrm{~B}$ ), with transverse white-yellow spots on oral surface (Figure $1 \mathrm{C}$ ). Each tentacle tapers to a point. White acrorhagi form a ring at the top of the parapet (Figure 1A). Oral disc flat, sometimes the anemone extends its oral area into a cone and the mesenterial insertions are marked as dark lines (Figure 1B, D).

\section{CNIDAE}

Spirocysts, basitrichs, microbasic p-mastigophores and holotrichs. The cnidae agree with previous descriptions of this species (Verrill, 1928; Dunn, 1974). We also found microbasic $p$-mastigophores $(23-32 \times 6-8 \mu \mathrm{m}(\mathrm{N}=30))$ in the column, not mentioned in previous descriptions. This type of cnidocyst was found in all examined specimens.
DISTRIBUTION OTHER THAN COSTA RICA (FIGURE 2) Indian Ocean-India: Mumbai (Parulekar, 1968), Kochi (England, 1987) and Mahim (Parulekar, 1968). Western Pacific-Japan: Hokkaido (Uchida, 1938) and Mutsu Bay (Uchida, 1938); Hong Kong (England, 1987, 1992); Korea: Geojedo Island (Song \& Lee, 1998). Central Pacific-USA: Hawaii (Verrill, 1928; Dunn, 1974; Cutress, 1977; England, 1987); Marshall Islands: Enewetak Atoll (Cutress \& Arneson, 1987). Eastern Pacific-Ecuador: Galápagos Islands (Fautin et al., 2007).

\section{DISCUSSIDN}

The examined specimens agree with those described by Dunn (1974) and Fautin et al. (2007). The colour, although often

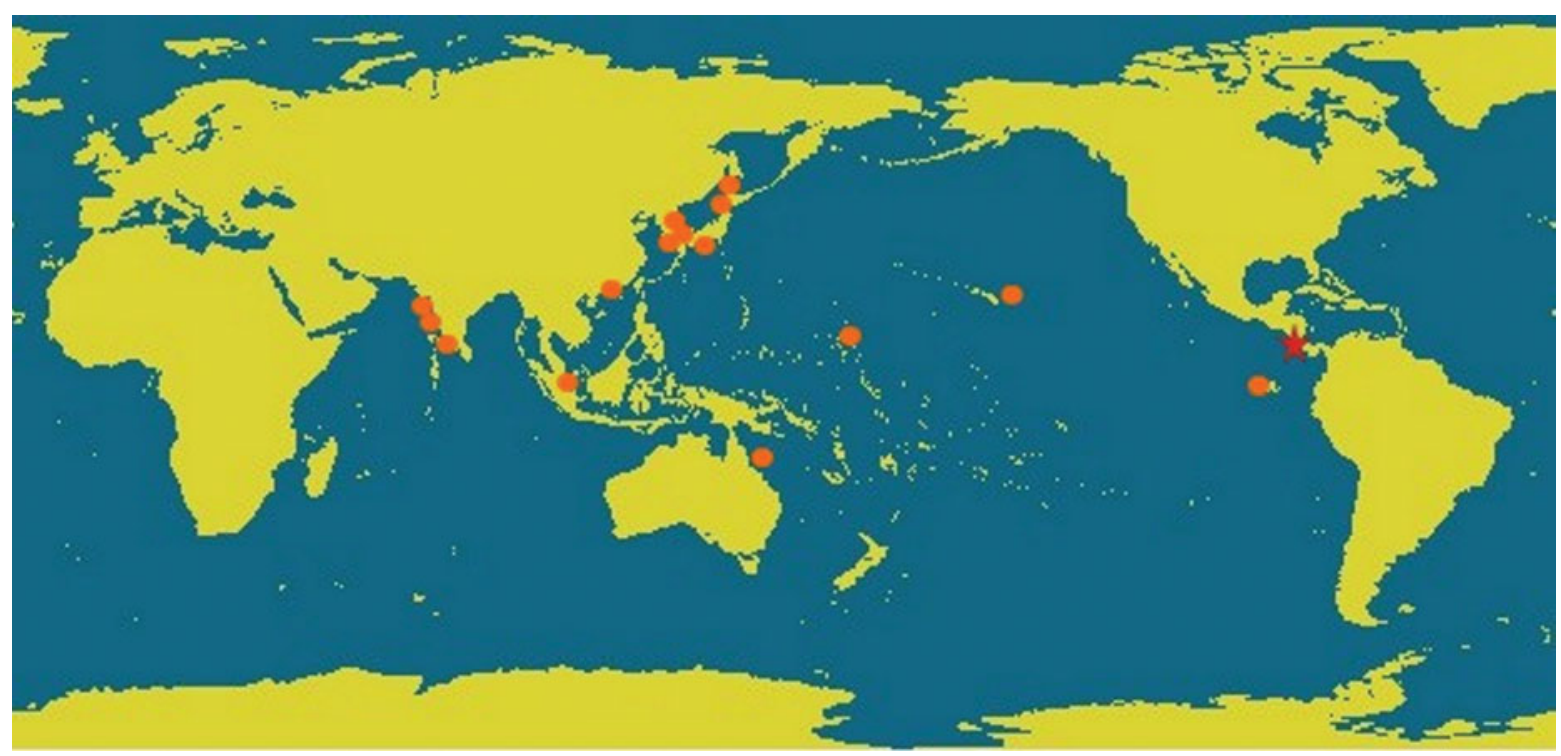

Fig. 2. Anthopleura nigrescens (Verrill, 1928): worldwide distribution; previous records (orange circles); the new record for Central America (red star). 
unreliable as a systematic character in sea anemones, is very consistent in the examined specimens (Figure 1) perhaps due to asexual reproduction. The variability in colour of this species was reported by Dunn (1974). This is the first record of $A$. nigrescens for the Pacific coast of Central America. In the eastern tropical Pacific, this species has only been found in the Galápagos Islands, where it is common in the intertidal zone (Fautin et al., 2007; Hickman, 2008). In light of the previous records for other regions of the Pacific Ocean and also the Indian Ocean, we can consider this sea anemone as widely distributed in the Indo-Pacific (Figure 2). The lack of previous records of $A$. nigrescens, despite several surveys on the Pacific coast of Costa Rica in the last years support the idea of a recent introduction of this species. Although this new record increases the biodiversity of sea anemones from Costa Rica, more studies are necessary in order to obtain a more complete inventory of these poorly known invertebrates.

\section{ACKDWLEDGEMENTS}

We are grateful to Dr Marymegan Daly for her constructive comments and improvement of the English version of this manuscript; and to Oscar Pacheco Prieto for the images of A. nigrescens included in this paper.

\section{REFERENCES}

Carlgren O. (1949) A survey of the Ptychodactiaria, Corallimorpharia and Actiniaria. Kunliga Svenska Vetenskapsakademien Handlingar 1, $1-121$.

Cutress C.E. (1977) Corallimorpharia, Actiniaria, Ceriantharia. In Devaney D.M. and Eldredge L.G. (eds) Reef and shore fauna of Hawaii. Honolulu: Bishop Museum Press, pp. 130-147.

Cutress C.E. and Arneson C.A. (1987) Sea anemones of Enewetak Atoll. In Devaney D.M., Reese E.S., Burch B.L. and Helfrich P. (eds) The natural history of Enewetak Atoll. Washington, DC: Office of Scientific and Technical Information, US Department of Energy, pp. $53-62$.

Dunn D.F. (1974) Redescription of Anthopleura nigrescens (Coelenterata, Actiniaria) from Hawaii. Pacific Science 28, 377-382.

England K.W. (1969) Anthopleura elatensis n. sp. (Actiniidae: Actiniaria) from the Red Sea. Israel Journal of Zoology 18, 1-7.

England K.W. (1987) Certain Actiniaria (Cnidaria, Anthozoa) from the Red Sea and tropical Indo-Pacific Ocean. Bulletin of the British Museum (Natural History) 53, 205-292.
England K.W. (1991) Nematocysts of sea anemones (Actiniaria, Ceriantharia and Corallimorpharia: Cnidaria): nomenclature. Hydrobiologia 216/217, 691-697.

England K.W. (1992) Actiniaria (Cnidaria: Anthozoa) from Hong Kong with additional data on similar species from Aden, Bahrain and Singapore. In Morton B. (ed.) The marine flora and fauna of Hong Kong and southern China III. Proceedings of the 4th International Marine Biological Workshop. Hong Kong: Hong Kong University Press, pp. 699-705.

Fautin D.G. (2011) Hexacorallians of the world. Available at: http:// geoportal.kgs.ku.edu/hexacoral/anemone2/index.cfm (accessed 6 February 2012).

Fautin D.G., Hickman Jr C.P., Daly M. and Molodtsova T. (2007) Shallow-water sea anemones (Cnidaria: Anthozoa: Actiniaria) and tube anemones (Cnidaria: Anthozoa: Ceriantharia) of the Galápagos Islands. Pacific Science 61, 549-573.

Fautin D.G., Tan S.H. and Tan R. (2009) Sea anemones (Cnidaria: Actiniaria) of Singapore: abundant and well-known shallow-water species. Raffles Bulletin of Zoology 22, 121-143.

Hickman C.P. Jr (2008) A field guide to corals and other radiates of Galápagos. Lexington, VA: Sugar Spring Press, $162 \mathrm{pp}$.

Mathew K. (1967) Observations on Anthopleura nigrescens (Verrill). Bulletin of the Department of Marine Biology and Oceanography, Trivandrum University, India 3, 41-44.

Parulekar A. (1968) Sea anemones (Actiniaria) of Bombay. Journal of the Bombay Natural History Society 65, 138-147.

Song J.I. and Lee I.S. (1998) Fauna of anthozoans from adjacent waters of Geojedo Island in Korea. Korean Journal of Systematic Zoology 14, 229-242.

Uchida T. (1938) Actiniaria of Mutsu Bay. Scientific Reports of the Tohoku Imperial University, Fourth Series (Biology) 13, 281-317.

and

Verrill A.E. (1928) Hawaiian shallow water Anthozoa. Bernice P. Bishop Museum Bulletin 49, 3-30.

\section{Correspondence should be addressed to:}

F.H. Acuña

Instituto de Investigaciones Marinas y Costeras, CONICET

Facultad de Ciencias Exactas y Naturales

Universidad Nacional de Mar del Plata

Funes 3250, 7600 Mar del Plata. Argentina

email: facuna@mdp.edu.ar 